\title{
CIRCULATORY MEASUREMENTS IN PATIENTS WITH RHEUMATIC HEART DISEASE BEFORE AND AFTER THE ADMINISTRATION OF DIGITALIS ${ }^{1}$
}

By SOMA WEISS AND LAURENCE B. ELLIS

(From the Thorndike Memorial Laboratory, Boston City Hospital, and the Department of Medicine, Harvard Medical School, Boston)

(Received for publication July 30, 1929)

THE PROBLEM

Evidence is available that a number of mechanisms are responsible for the clinical manifestations of cardiovascular diseases. Confusion exists, nevertheless, because results of experimental and clinical studies of a single aspect of the circulation are still offered as an explanation or index of the multiform nature of circulatory failure. All such attempts to find a common factor for the explanation of symptoms and signs of cardiovascular diseases have failed so far. In considering the number of variables involved it is questionable whether such endeavors ever will be more than partially successful.

In studying the beneficial effect of a therapeutic agent in cardiovascular diseases, it is essential that the pathologic physiology and morphology of the disease as manifested in each patient studied should be known before the administration of the drug. Cohn (1) pointed out the importance of considering the action of digitalis in its relation to various factors which might constitute a particular variety of heart failure. He used the type of cardiac rhythm, the presence or absence of edema, and high blood pressure, as a basis for classification of heart failure. A number of other classifications have been suggested. The value of such divisions depends upon the fundamental relevance of the factors used as a basis for the classification. A complete understanding of circulatory failure requires, however, a knowledge of a number of other physical and chemical characteristics of the circulation,

1 This investigation was aided by a grant from the William W. Wellington Research Fund of the Harvard Medical School. 
in addition to that of the rhythm, the presence or absence of edema, and of high blood pressure.

In studying the efficiency of function of the cardiovascular system, it is of primary importance to know among these other characteristics the energy consumed by the heart and corresponding cardiac work, the amount of blood delivered with a known velocity and pressure, and the body metabolism in a given unit of time. Of these functions the energy consumption of the heart can not be measured in man. In normal subjects the other functions can be ascertained. In patients with valvular heart disease, although the cardiac work can not be calculated from the cardiac output and arterial pressure, nevertheless, measurements of these functions give the best quantitative estimation of cardiac work and efficiency available at present.

A number of studies have been conducted during recent years on the velocity of blood flow, cardiac output, tissue utilization of oxygen, circulatory blood volume, and certain chemical constituents of the blood in patients with cardiovascular diseases. The results and interpretations of these investigations conflict in part, because some of the methods applied were unreliable, and, furthermore, because no careful correlation was made between the clinical condition of the patients and the results obtained. Without such a clear and precise correlation the results fail to improve our knowledge of the disease as a whole, but throw light rather on the method used and on the variability of the behavior of that aspect of the circulation, which was measured. The purpose of the study presented here was to investigate a number of aspects of the circulation before and after the administration of digitalis in patients who were suffering from chronic rheumatic heart disease and who exhibited approximately the same clinical degree of circulatory failure. It was hoped that such a study would lead to a better understanding of the mechanism of the circulation in rheumatic heart disease, as well as of the effect of digitalis in this condition.

\section{PLAN OF INVESTIGATION}

It was thought that repeated observations of a few suitable and trained patients would disclose the interrelation of certain factors in the circulation better than single tests in a large number of cases. Four young patients were studied. All four had suffered from rheu- 
matic infection, and as a result exhibited markedly enlarged hearts and clinical evidence of distorted mitral and aortic valves. In case I, the tricuspid valves were also involved. The nature of the distortion of the valves, as in the majority of cases with rheumatic heart disease, was combined stenosis and insufficiency. In addition, there was clinical and teleroentgenological evidence of chronic adhesive pericarditis. There was indirect evidence of toxic myocardial involvement as a result of rheumatic fever. The morphological changes of the heart, therefore, represented the effect of severe generalized infection of the cardiac structures (rheumatic pancarditis) (figs. 1,2 and 3).

The cardiac rhythm was normal sinus rhythm in all cases. Clinical and roentgen-ray studies failed to reveal pulmonary congestion. All of the patients were comfortable during rest and without symptoms or signs of circulatory failure, but on very moderate exertion became dyspneic and had a marked rise in the cardiac rate. Patients 1 and 3 subsequently died as a result of an acute flare-up of rheumatic infection. At the time of the performance of the circulatory measurements, however, neither showed evidence of congestive failure or progressive decrease in the functional capacity of the circulation. In Hoffmann's (2) classification of circulatory failure, the circulation of the patients studied would be entered as "relatively insufficient" as their hearts failed against a very moderate amount of muscular work. According to Mobitz's conception (3), all patients were in a state of circulatory failure. In the classification approved by the American Heart Association (4), the four patients, since they were unable to carry on ordinary physical activity without discomfort, and were, therefore, forced to limit their activity greatly, belong in group $\mathrm{D}$, class $2 \mathrm{~b}$.

All four patients had had a rest period previous to the beginning of the circulatory measurements. After their condition became stationary and their coöperation had been gained, repeated measurements were made of the pulse rate, blood pressure, cardiac output per minute, respiratory minute volume, circulating blood volume, relative and mean velocity of blood flow, and vital capacity of the lungs. After the control period, large doses [0.84 to 1.40 gram (12 to 20 cat units)] of digitalis, as tincture or powder, were administered within a period of 24 hours, followed by a maintenance daily dose of 0.07 to 0.21 gram of the powder. Immediately following the administration of digitalis, 
as well as during the six weeks period in which each patient received a maintenance dose, the measurements were repeated once or twice a week. The administration of digitalis was then stopped for three weeks, to permit the elimination of digitalis from the body. After this period had elapsed large therapeutic doses were administered once more, so that the full effect of the drug was obtained a second time within 24 to 48 hours. The tests were repeated both during the stage of elimination and after the second digitalization. It was thought that this procedure would make it possible to distinguish changes caused by the disease from those due to taking digitalis.

\section{METHODS}

To estimate the circulatory efficiency of the patients, simple exercise tests, such as walking, or bending from a recumbent to a vertical position were used. Repetition of a given test in any one patient was carried out in identical fashion. The increase of the heart rate with exercise and the return to normal following it were observed. The change in respiration and the statement of the patient regarding his subjective sensations were also considered. In our experience, the curve of the return of the cardiac rate after a standard amount of exercise is a valuable functional test of cardiac reserve.

The cardiac output per minute was measured by the method of Field, Bock, Gildea and Lathrop (5). The patients were in semirecumbent position in bed during the performance of the test. Usually seven "alveolar" and "virtual venous" gas samples were analyzed. The metabolism was estimated by the Tissot method. The respiratory quotients were always calculated in order to ascertain whether the ventilating functions of the lungs were normal. The blood volume was estimated by the dye injection method of Keith, Rowntree and Geraghty (6). The velocity of the blood flow between the antecubital vein and the facial vessels was tested by the histamine method (7). The mean velocity of the circulation was calculated from the cardiac output per minute, and the total blood volume. A Collins' spirometer was used for the estimation of the vital capacity of the lungs. All the tests were performed with patients in post-absorptive state.

The potency of the digitalis preparation administered was tested according to the method of Hatcher and Brody (8). This showed that 0.07 gram of the powdered leaf corresponded to one cat unit. A combined digitalis and ouabian test performed at 24-hour intervals indicated that the digitalis used contained but a small amount of the digitalis bodies which are rapidly eliminated (9). Electrocardiographic tracings were taken to ascertain the effect of digitalis on the heart.

\section{RESULTS}

The results of the observations are presented in tables 1 to 4 and are graphically represented in charts 1 to 4 . In all, 75 measurements of 


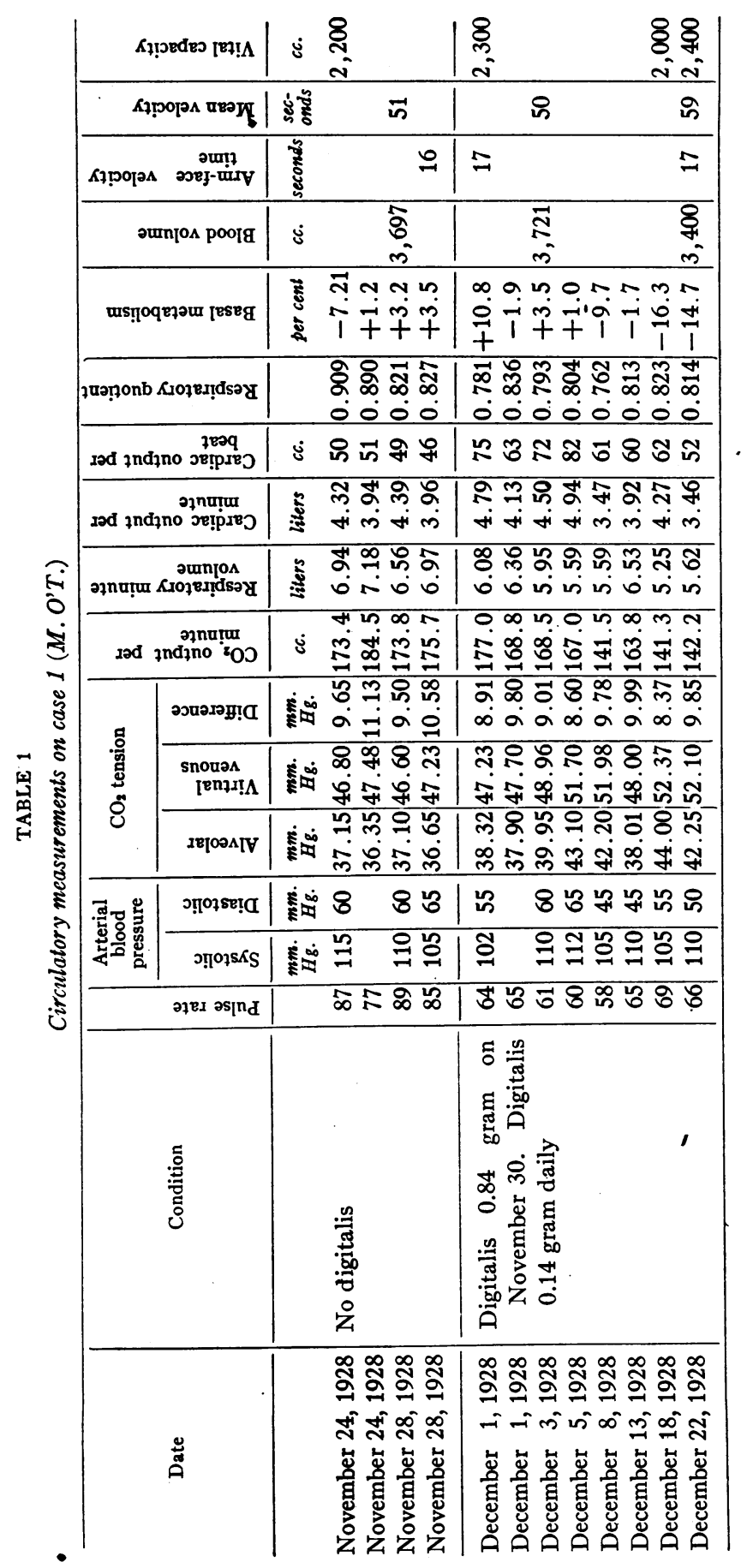




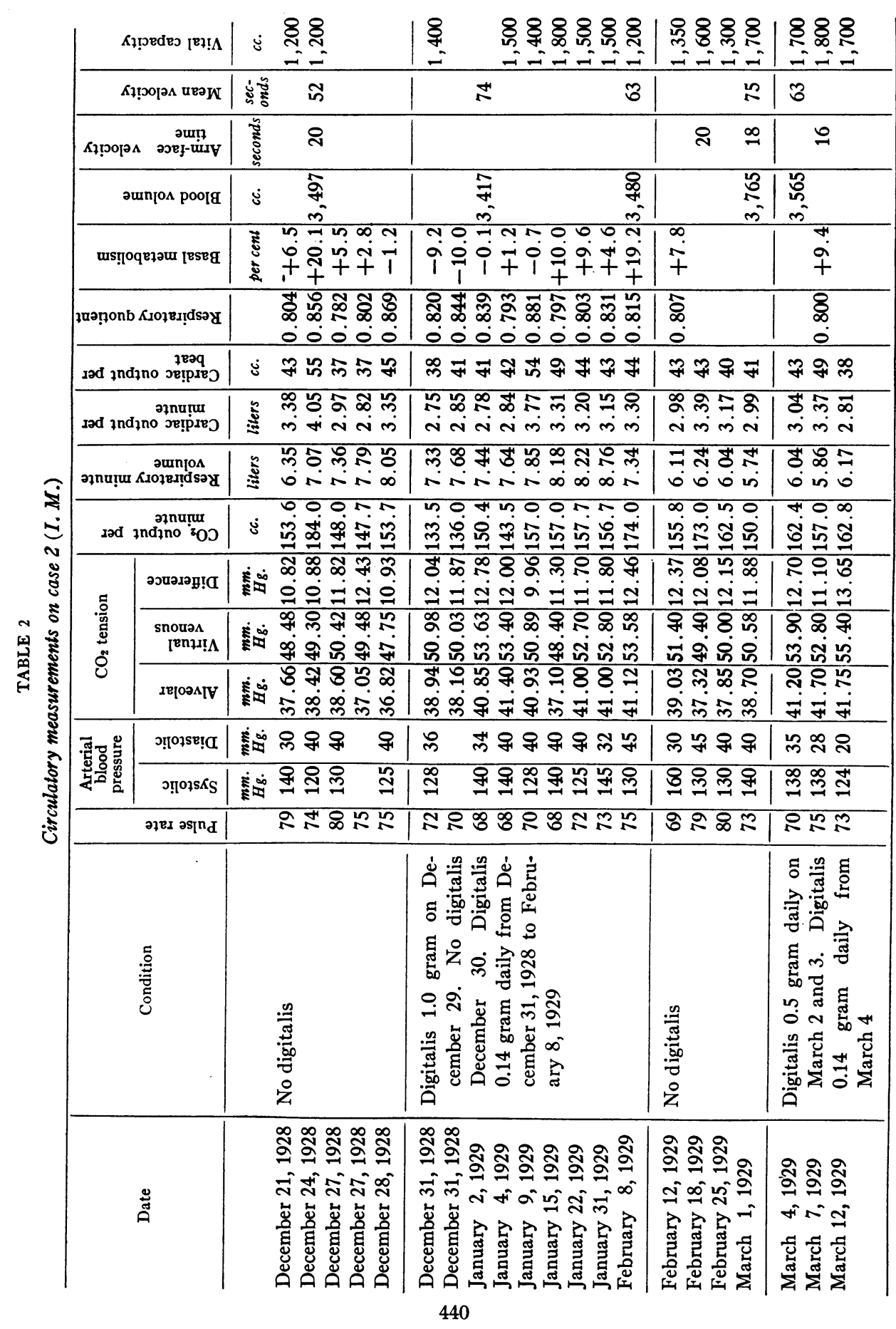




\begin{tabular}{|c|c|c|c|c|c|c|}
\hline & & odde pon:L & $\dot{8}$ & 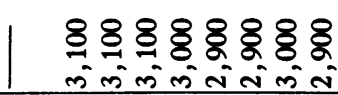 & 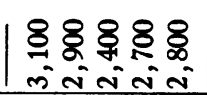 & 8 \\
\hline & & ород шәәК | & 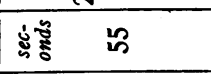 & 8 & 8 & \\
\hline & 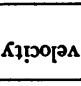 & 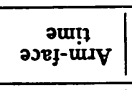 & $\vec{d}$ & $\begin{array}{l}0 \\
d \\
d\end{array}$ & & \\
\hline & & nos poolg & $\begin{array}{l}8 \\
8 \quad 8 \\
\text { in } \\
\end{array}$ & $\begin{array}{l}\text { 总 } \\
\text { in } \\
\text { in }\end{array}$ & 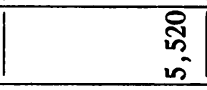 & : \\
\hline & ws:100 & 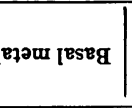 & 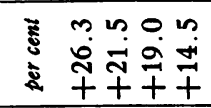 & 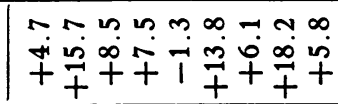 & 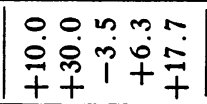 & 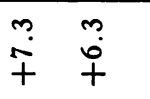 \\
\hline & uaponb. & 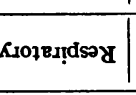 & 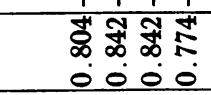 & 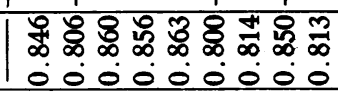 & 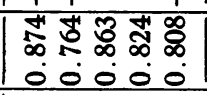 & 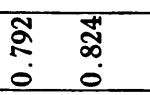 \\
\hline & Iad ?nd? & ino & ப & 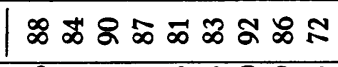 & $\infty \curvearrowleft \approx ล ์$ & నूล \\
\hline & rad $7 \mathrm{ndz}$ & 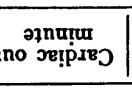 & 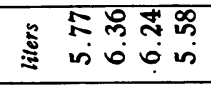 & 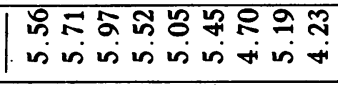 & 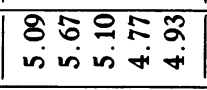 & 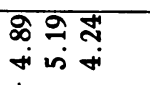 \\
\hline & ənagur & 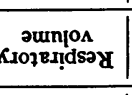 & 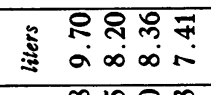 & 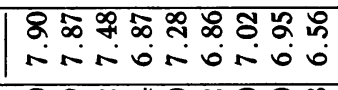 & 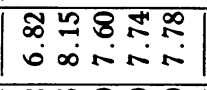 & \begin{tabular}{l}
$\infty$ \\
$0.8 \%$ \\
\hdashline \\
\hdashline
\end{tabular} \\
\hline & & 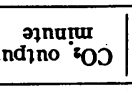 & 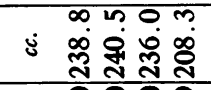 & $\begin{array}{lll}0 \\
0 \\
0\end{array}$ & 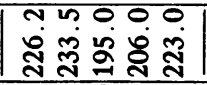 & क्ष \\
\hline & & әзадәуча | & 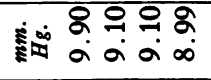 & 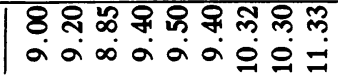 & 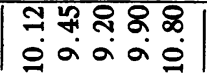 & 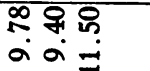 \\
\hline & 鄫 & 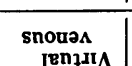 & 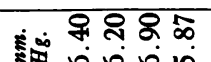 & q & 궁의 웅 8 & o $80 \overline{0}$ \\
\hline & हैं & & 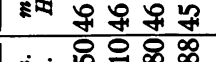 & 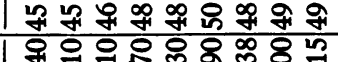 & 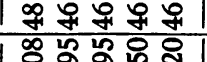 & $\begin{array}{ll}8 \\
8\end{array}$ \\
\hline & & $\operatorname{reposan} \mid$ & 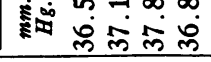 & 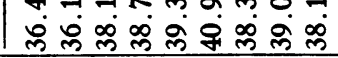 & sid & 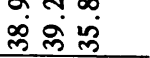 \\
\hline & 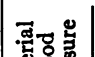 & 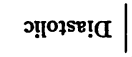 & 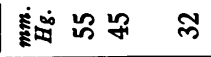 & 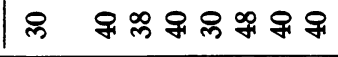 & 98 연 & 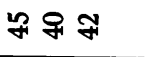 \\
\hline & 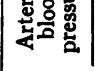 & 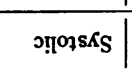 & 我点음 & 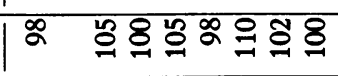 & 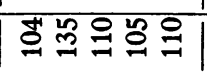 & 읔표 \\
\hline & & ozter ssinn | & $\infty \infty$ & 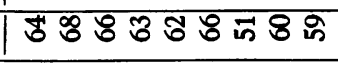 & $\square$ व & $88 \%$ \\
\hline & & 密 & 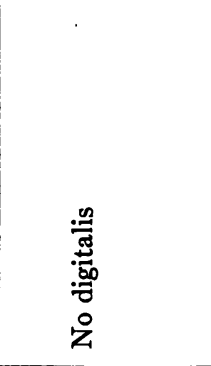 & 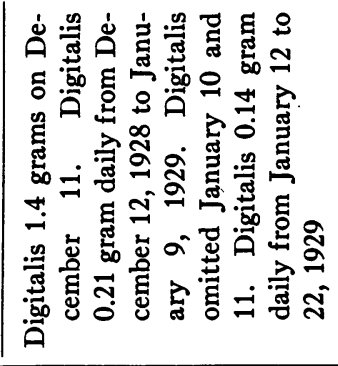 & 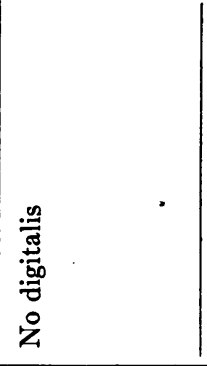 & 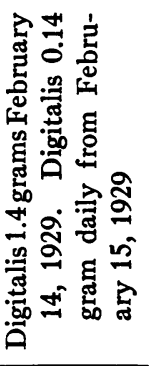 \\
\hline & & 离 & 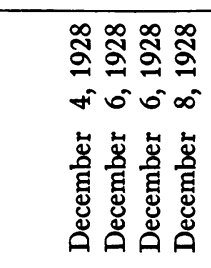 & 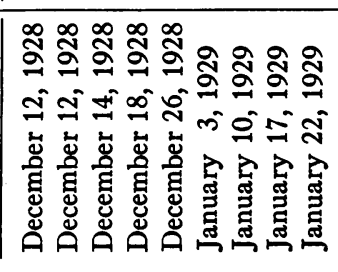 & 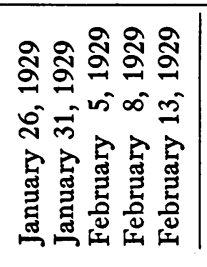 & 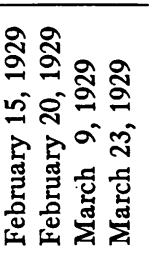 \\
\hline
\end{tabular}




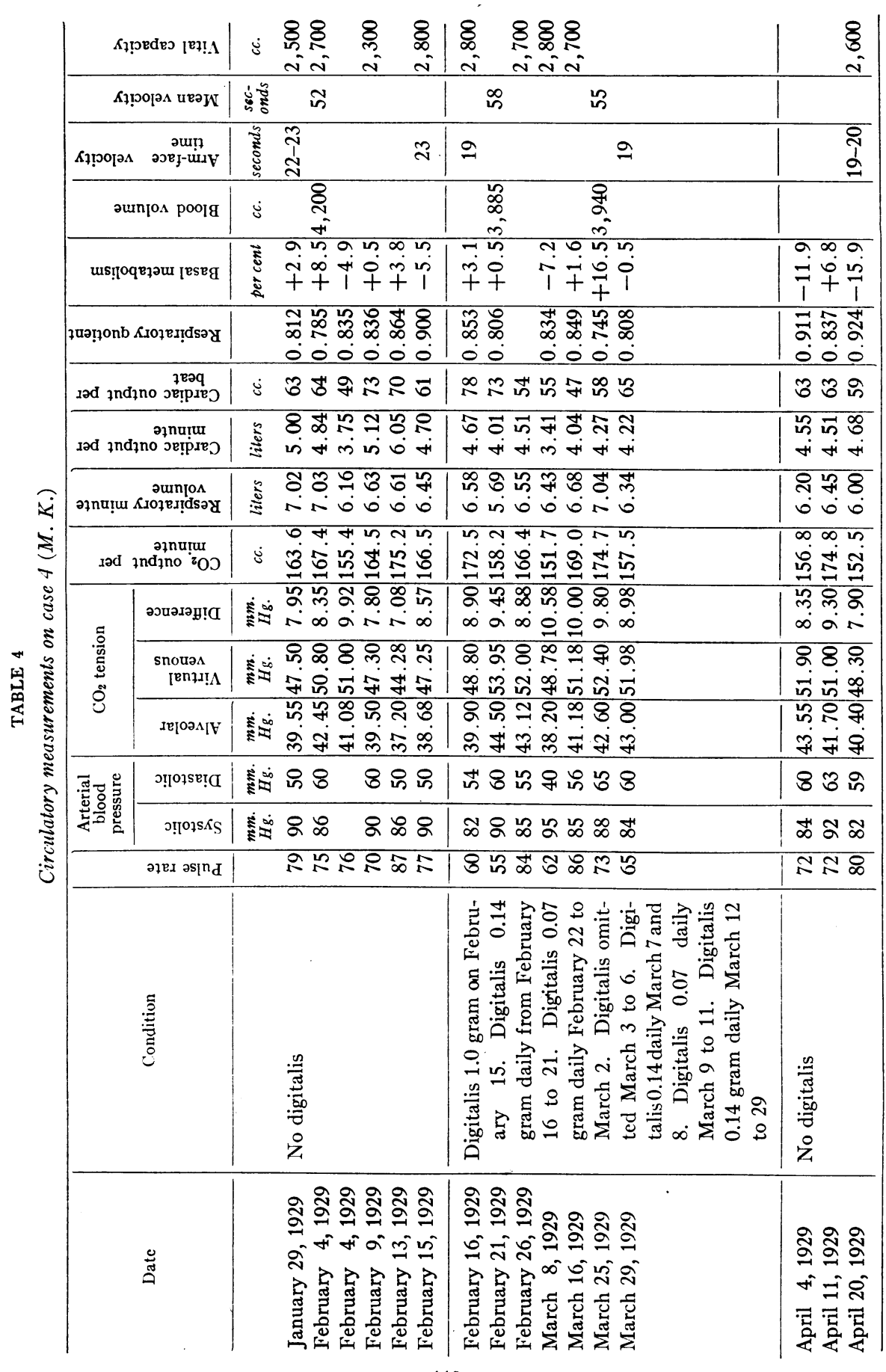




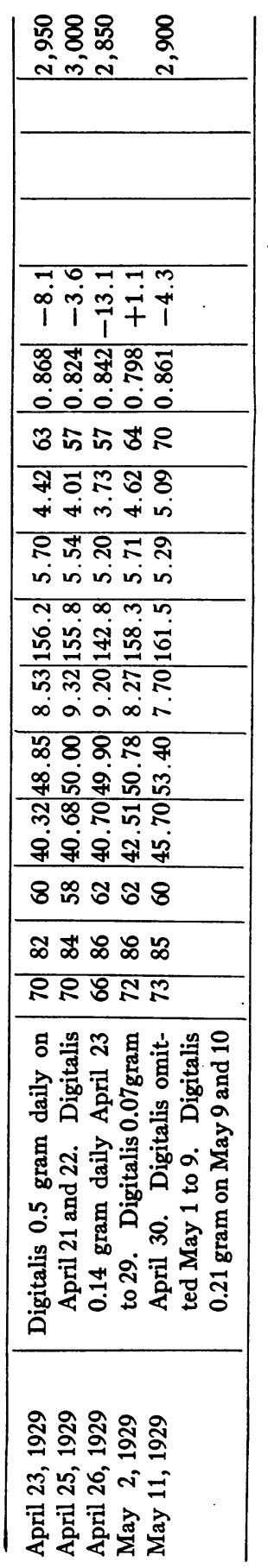




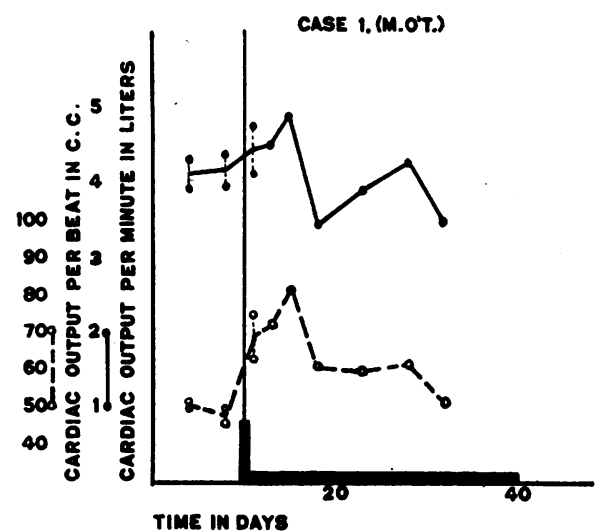

Chart 1. Graphic Representation of the Cardiac Output per Minute, and per Beat Before and During the Administration of Digitalis in CASE I

The thick black line along the abscissa represents the relative amount of digitalis administered.

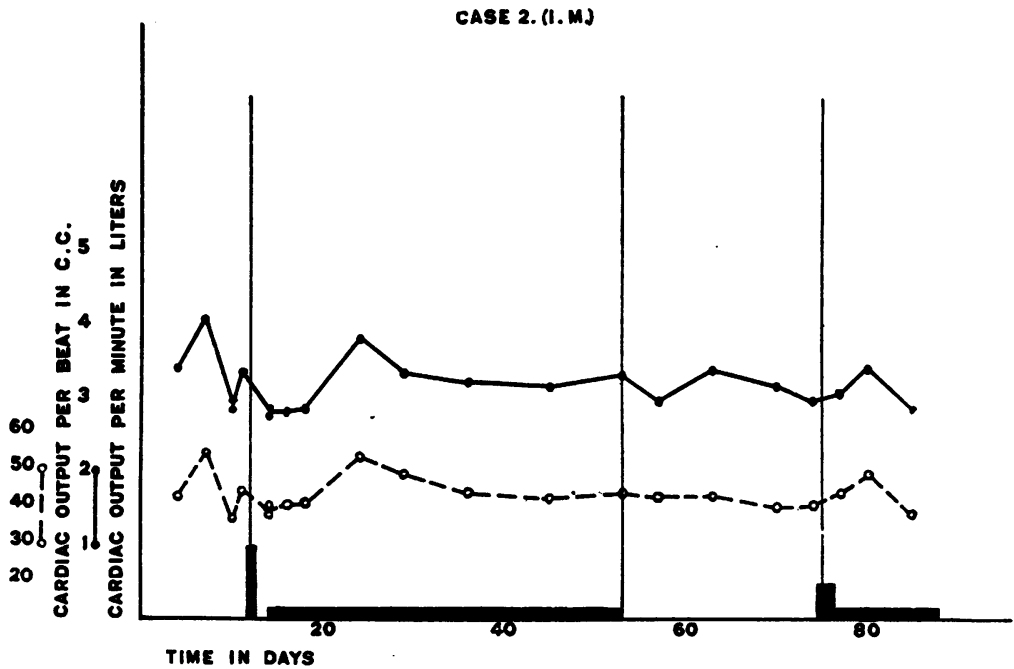

Chart 2. Graphic Representation of the Cardiac Output Before, During aNd After the Administration of Digitalis in Case II

The thick black lines along the abscissa represent the relative amount of digitalis administered. 


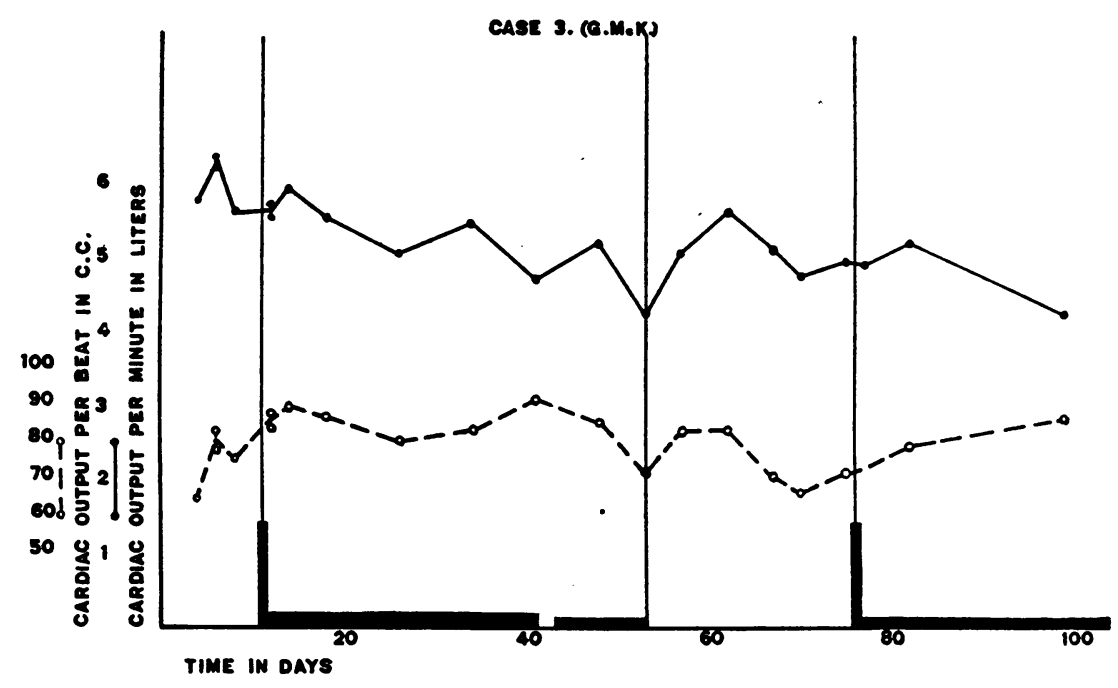

Chart 3. Graphic Representation of the Cardiac Output per Minute and per Beat Before, During and After the Administration of Digitalis IN CASE III

The thick black lines along the abscissa represent the relative amount of digitalis administered.

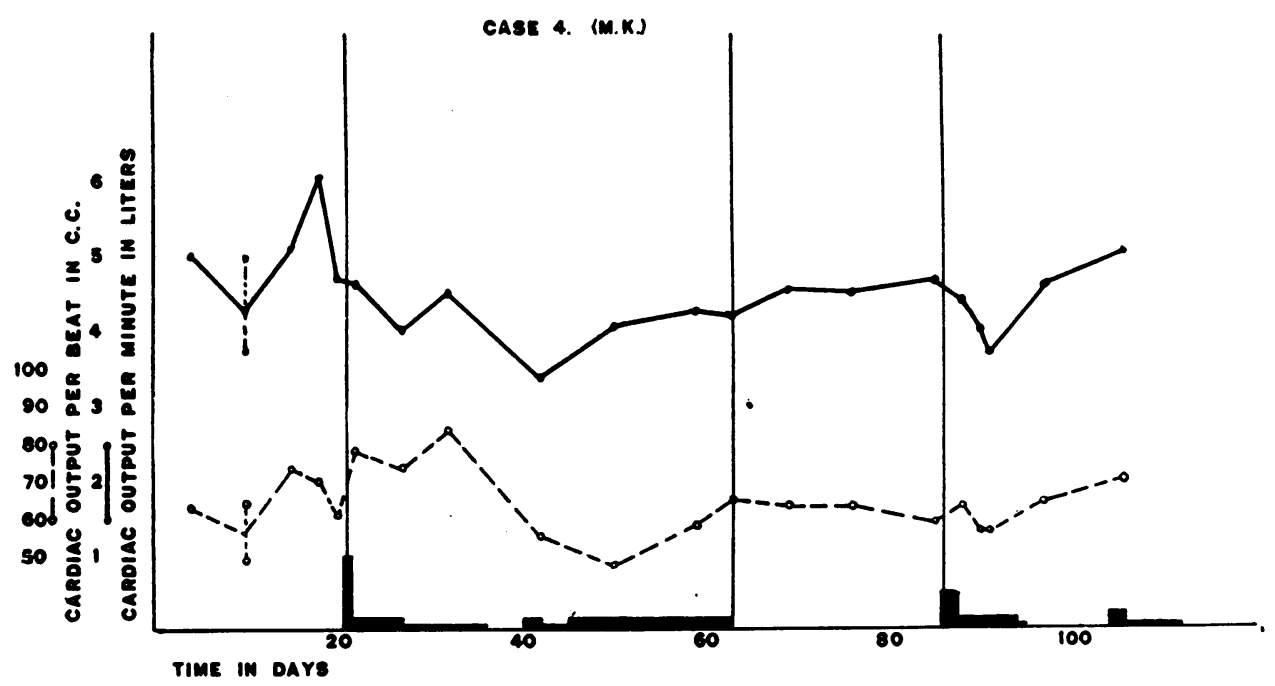

Chart 4. Graphic Representation of the Cardiac Output per Minute and per Beat Before, During and After the Administration of Digitalis IN CASE IV

The thick black lines along the abscissa represent the relative amount of digitalis administered. 
the cardiac output of the four patients studied were made at different intervals of time. A summary of the clinical description of the patients, as well as some of the laboratory findings not included in the tables and charts, are appended.

\section{Interpretation of results obtained before the administration of digitalis}

It is significant that the alveolar carbon dioxide tension, as well as the respiratory minute volume, were within normal limits. These findings, together with the respiratory quotients, indicate that the respiratory function of the lungs was normal, and therefore that the physiological conditions for the application of the method for the measurements of the cardiac output were suitable. The reduced vital capacity suggests that the amount of blood in the lungs was probably increased, but the absence of cyanosis and edema, dyspnea, orthopnea and pulmonary venous congestion at rest shows that the aeration of the blood in the pulmonary capillaries was normal. The average cardiac output per minute previous to the administration of digitalis was 4.2 liters in case $1 ; 3.3$ liters in case $2 ; 6.0$ liters in case $3 ; 4.9$ liters in case 4 . The average cardiac output per minute as found in the four patients was 4.6 liters. The average cardiac output per minute in 12 young normal adults, obtained by the same methods under identical conditions, was 6.8 liters. The average cardiac output in the patients was therefore 32 per cent lower than the normalaverage. The variations in the blood flow were greater than in normal individuals. This we believe is due to the unstable circulation of the patients.

Since the average pulse rate at rest was 79 , the average cardiac output per beat was $49 \mathrm{cc}$. in case $1,43 \mathrm{cc}$. in case $2,76 \mathrm{cc}$. in case 3 , and $63 \mathrm{cc}$. in case 4 ; and since the average cardiac output per beat in the 12 normal individuals was $105 \mathrm{cc}$., the average cardiac output per beat in these patients was 44 per cent less. The difference between the alveolar and venous carbon dioxide tension, in its relation to rate of blood flow, is an important index of the efficiency of the circulation. The average difference between alveolar and virtual carbon dioxide tension was $9.7 \mathrm{~mm} .(10.2,11.2,9.3,8.1 \mathrm{~mm}$. in the four patients respectively) of mercury as compared with the average difference of $7.4 \mathrm{~mm}$. found in normal persons. Although the average 
difference in the patients is higher, the values are within the upper limit of normal. It is, therefore, of interest to notice that while the average cardiac output was lower than normal, the carbon dioxide transportation was higher. Similarly, the oxygen utilization between the capillaries and tissues was greater in the patients than in normal subjects, as is shown by the fact that the volume of blood flow corresponding to the consumption of $100 \mathrm{cc}$. of oxygen was 2.1 liters in the patients while it was 2.8 liters in the twelve control normal subjects. This would suggest that the capillary circulation and the tissues aid in compensating for the failing cardiac function, by responding with a more efficient exchange of blood gases. The average arm to face circulation time was 22 seconds, and the average mean circulation time, 53 seconds. These values are within the limits of normal, although the average mean circulation time of the patients is higher than that of normal individuals. It was shown in a previous study (7) also that the velocity of blood flow between the antecubital vein and the facial vessels is essentially normal at rest in compensated patients suffering from cardiovascular diseases.

\section{Interpretation of results after the administration of digitalis}

Previous to the administration of digitalis the four patients had relatively slow regular heart rates when at rest. On slight muscular exertion, however, the rate rose as high as 120 to 150 ; after slight exercise the rate returned to normal over an abnormally long period of time. Following the administration of digitalis (table 5), the average pulse rate became lower, though the evidence of clinical improvement was not definite, at least in the state of rest. On performing the standard exercise, however, the patients showed distinct improvement, in that the pulse rate did not rise as high during and after the exercise and returned to a normal level within a much shorter period. Dyspnea, palpitation, and subjective sensations associated with the exercise were also less than before digitalization. One can attribute such benefit to the administration of digitalis, especially if one considers that there is evidence that the amount of energy used up by the heart in performing a given exercise is proportional to the number of heart beats irrespective of the work accomplished (10).

The cardiac output per minute showed no constant change after 
the administration of large therapeutic doses. In case 1 there was a tendency to slight rise; in cases 2 and 3 there was no change, while case 4 showed slight reduction. Considering the marked spontaneous variations during the control period, it is questionable whether significance can be attached to such change. Three of the patients $(1,2$ and 4) showed first a rise in the cardiac output per beat, followed by a gradual slight fall during the period of maintenance dosage. Similarly, no definite change developed during the three weeks while digitalis was in course of elimination, as well as following the second digitalization.

TABLE 5

Average values for the four cases of pulse rate and of cardiac output per minute and per beat, before and during digitalis administration

\begin{tabular}{|c|c|c|c|c|c|c|c|c|c|c|c|c|}
\hline \multirow[b]{2}{*}{ Case } & \multicolumn{3}{|c|}{$\begin{array}{l}\text { Control period, } \\
\text { no digitalis }\end{array}$} & \multicolumn{3}{|c|}{$\begin{array}{c}\text { First period of } \\
\text { digitalization }\end{array}$} & \multicolumn{3}{|c|}{$\begin{array}{l}\text { Control period, } \\
\text { digitalis elimination* }\end{array}$} & \multicolumn{3}{|c|}{$\begin{array}{c}\text { Second period of } \\
\text { digitalization }\end{array}$} \\
\hline & 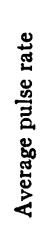 & 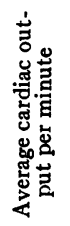 & 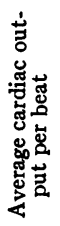 & 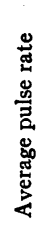 & 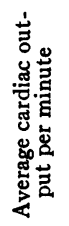 & 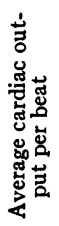 & 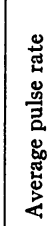 & 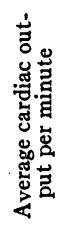 & 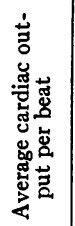 & 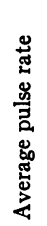 & 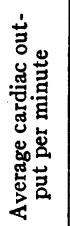 & 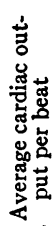 \\
\hline & & liters & $c c$. & & liters & $\omega c$. & & liters & $c c$. & & liters & $c c$. \\
\hline 1. (M. O'T.) & 84 & 4.15 & 49 & 64 & 4.19 & 66 & & & & & & \\
\hline 2. (I. M.) & 77 & 3.31 & 43 & 71 & 3.11 & 44 & 76 & 3.08 & 40 & 73 & 3.07 & 43 \\
\hline 3. (G. McK.) & 80 & 5.99 & 76 & 62 & 5.26 & 85 & 69 & 4.85 & 69 & 61 & 4.77 & 80 \\
\hline 4. (M. K.) & 77 & 4.91 & 63 & 69 & 4.25 & 61 & 80 & 4.68 & 59 & 70 & 4.37 & 62 \\
\hline
\end{tabular}

* Only determinations performed during the third week of the excretion period are averaged.

The arm to face circulation showed no change which could be definitely attributed to the effect of giving digitalis, nor did the mean velocity of blood flow. In case 2 , it was prolonged from 52 seconds to 74 seconds and to 63 seconds during the administration of digitalisafter the administration of digitalis it became 75 seconds, and after the second administration it was 63. No constant change in the circulating blood volume after the administration of digitalis was observed. 


\section{DISCUSSION}

A. The mechanism of the circulation in the stage of moderate cardiac failure

Previous to the introduction of methods for circulatory measurements in man, the effect of cardiovascular disease on the circulation was considered comparable to that of an inefficient water pump. This conception was based on morphological observations. Critical observation with the aid of new methods soon indicated that the function of the circulation in heart disease is complicated. Plesch (11), Lundsgaard (12), Meakins, Dautrebande and Fetter (13), Rabinowitch (14), Mobitz (3) and Lauter and Baumann (15), observed normal or reduced cardiac output in patients with moderate circulatory failure. Objection may be made, however, to the conclusions of these authors because of the doubtful value of some of the methods used (16). In contrast to their findings are those of Eppinger, Kisch and Schwarz (17), who on the basis of an extensive study of various aspects of the circulation, conclude that circulatory failure is a condition of disordered metabolism, in which faulty resynthesis of lactic acid into glycogen plays an important rôle. In consequence of this fault, the acid content of the body and the velocity of the blood flow are increased, as may be inferred from increase in the minute volume output.

While it is appreciated that the failure of the circulation is associated with important changes in the physico-chemical constituents of the blood and tissues, nevertheless, it is difficult to conceive how, in a condition in which the site of the primary destructive processes is the heart, the first appreciable pathological change should occur in the metabolism of the tissues.

The conception of Eppinger, Kisch and Schwarz that in the first stage of circulatory failure there is an increase in the velocity of blood flow failed to be confirmed in a series of investigations by Blumgart and Weiss (18) (19) (20) (21) (22). In using direct measurements of the circulation time Blumgart and Weiss observed not an increase but a slowing both of the pulmonary and of the peripheral blood flow. Although there was no parallel between the degree of slowing and the intensity of clinical manifestation of failure in every case, a definite 
increase in the velocity of blood flow was never observed in heart failure. The circulation time and the cardiac minute output may not change correspondingly in circulatory failure, provided that simultaneously with increased cardiac output there is a marked increase in the cross sectional area of the vascular bed. Theoretically, the cardiac output may increase under such conditions while the velocity of blood flow remains unchanged or is even slowed. With unaltered arterial pressure such a condition must lead to increase in the circulating blood volume. An increase in blood volume may indeed occur in circulatory failure (23). A correlation of this phenomenon with the clinical condition of the patients shows, however, that the increase in blood volume usually occurs in the late stage of circulatory failure. But in this stage even Eppinger, Kisch, and Schwarz (17) believe that the blood flow is slowed.

Because of the simultaneous measurement of cardiac output, blood volume, and the relative and mean velocity of the blood flow we believe that the observations presented here on the four patients are of special significance for the understanding of circulatory failure. These observations fail, then, to support the conception of Eppinger, Kisch and Schwarz (17). The cardiac output, as well as the velocity of blood flow, were not increased, but on the contrary, the average values obtained in the patients were lower than those exhibited by normal individuals. The reduction was particularly marked in the cardiac output per beat. The utilization of oxygen and the elimination of carbon dioxide were more efficient than in an average normal subject. A correlation of the clinical conditions of the patients and the observations presented indicates that at rest a moderate reduction in the cardiac output and velocity, if associated with increased utilization of oxygen and increased carbon dioxide transportation of the blood, does not cause signs of circulatory failure.

In the light of the investigations presented, as well as in that of the available observations of others, our conception of the effect of progressive cardiac damage in rheumatic heart disease, with the patients at rest, may be summarized as follows. As a result of infection in the heart and distortion of valves, the heart muscle works with less efficiency. The cardiac output, velocity of blood flow and blood pressure are maintained, but with a greater consumption of energy 
by the heart. If the infection is active in the heart muscle, it is probable that the ratio between the total calories utilized by the heart and calories expended as kinetic energy is low. With the maintenance or advance of the infectious process, due to lack of economy in the cardiac work, the "cardiac reserve" gradually becomes reduced and the vital capacity becomes lowered. Lowered vital capacity may be due to an increased amount of blood in the lungs, but in addition, reflex disturbances between the heart and lungs may also play a rôle. At this stage the velocity of the blood flow and the cardiac output through the lungs may still be normal. Later the velocity of blood flow, as well as the cardiac output, becomes decreased at rest. Simultaneously with the reduction of velocity and of cardiac output the rate of the exchange of gases between the blood in the capillaries and the tissue cells becomes greater, and thereby the task of the circulation is fulfilled, at least when the patient is at rest. With progressive decrease of velocity of blood flow and decrease in cardiac output, the amount of blood in the venous system increases. The capillary circulation, although the relative amount of the gases is increased, is now unable to compensate for the advanced degree of cardiac failure. This leads to increased venous pressure, important changes in tissue metabolism, and to edema. According to this conception, with progressive cardiac failure the earliest changes which are manifest are in the reduction of the vital capacity and cardiac output per beat followed by decreased velocity of blood flow and cardiac output per minute, and finally by occasional increased blood volume and rise in venous pressure.

\section{B. Changes in the blood flow in man after the administration of digitalis}

In patients with circulatory failure in accordance with the earlier clinical conception, it was assumed and observed that digitalis increased the cardiac output and the velocity of blood flow (15) (29) (30) (31). On the basis of recent observations and experiments, the view is held that there is, on the contrary, a decrease (25) (26) (27) (28) (31). Eppinger, Papp and Schwarz (25) were the first who, after observing an increased cardiac output in patients with circulatory failure, noted a reduction in the amount of blood expelled from the left ventricle of one patient following the administration of digitalis. On 
the basis of this observation they suggested that the beneficial effect of digitalis manifested itself in a reduction of the cardiac output.

Weiss and Blumgart (32), using the radio-active deposit method, observed no change in the velocity of the pulmonary blood flow, of the peripheral venous blood flow, vital capacities, or the arterial and venous pressures of eight normal subjects following the administration of large therapeutic doses of strophanthin or tincture of digitalis. When strophanthin or digitalis were administered to fourteen patients suffering from cardiovascular disease, the velocity of the pulmonary blood flow became increased in seven, was unaltered in four, while in three patients it was definitely decreased. These authors concluded that the velocity of blood flow in the pulmonary circuit is decreased in patients with circulatory failure. With clinical signs of improvement due to the administration of digitalis or to rest the velocity of the blood flow increases, although the degree of the patient's improvement and the change in velocity may not be parallel. Patients with symptoms and signs of congestive failure, when at rest, exhibited a greater tendency to show an increase in the velocity of the pulmonary blood flow than patients whose hearts were compensated at rest.

The bulk of evidence reported in the literature and observations presented here do not therefore support the contention that digitalis induces its beneficial effect by reducing the cardiac output per minute, but favors the conception that the administration of digitalis to patients with rheumatic cardiovascular disease with regular rhythm and with moderate failure of the circulation, either produces no essential change in the velocity and cardiac output per minute or increases it. In the four patients studied, the digitalis administered did not essentially influence the cardiac output per minute. The average value was slightly reduced, but it is doubtful, in face of spontaneous variations, whether this reduction can be attributed directly to the effect of digitalis. Similarly, the cardiac output per beat was essentially unchanged. Emphasis is to be placed on the fact that failure to observe an increase in the cardiac output per minute during rest does not necessarily indicate that digitalis fails to benefit the patient. There are a number of other mechanisms through which digitalis, even with unchanged cardiac output or velocity of blood flow, may improve the circulation. Reduced heart rate may constitute per se an improve- 
ment, so far as economy of the cardiac function is concerned, and may suffice to check progressive failure and restore gradually the cardiac reserve. The effect of digitalis on nervous structures in maintaining important cardio-vasomotor reflexes may also have considerable significance. It is probable that circulatory measurements performed during and after exercise and before and after the administration of digitalis will throw added light on the effect of this drug. The observations also suggest that the pharmacologic effect of digitalis on animals and normal men is different from the therapeutic effect on patients. This conception gains support from previous observations (32). It is probable that the reason the blood flow of the patients reported here showed no distinct change after digitalization is due to the fact that during rest the rate of blood flow was but slightly reduced and the blood volumes were normal. The effect of digitalis on the blood flow depends on the degree of circulatory failure. Thus in the study of the therapeutic effect of digitalis a careful correlation of the condition of the patient and the circulatory measurements is essential.

\section{SUMMARY AND CONCLUSIONS}

1. Repeated circulatory measurements were performed before and after digitalization in four patients with rheumatic heart desease. The patients were comfortable at rest, exhibited no clinical evidence of congestive failure, but showed marked reduction in their functional capacity on attempting any muscular activity.

2. The vital capacity of the lungs, the average cardiac output per minute and per beat, and the mean velocity of the blood flow were well below the normal. The velocity of the blood flow from the arm to face and the circulating blood volume were normal.

3. While the average rate of blood flow was reduced as a result of heart disease, the exchange of carbon dioxide and oxygen between the capillaries and tissues per unit of the circulating blood volume was increased. The capillary circulation responded with increased efficiency in compensation for the impaired cardiac function.

4. Although all the patients showed clinical improvement as a result of the administration of digitalis, the cardiac output, the velocity of blood flow, the circulating blood volume and the vital capacity of the lungs showed no significant changes. 


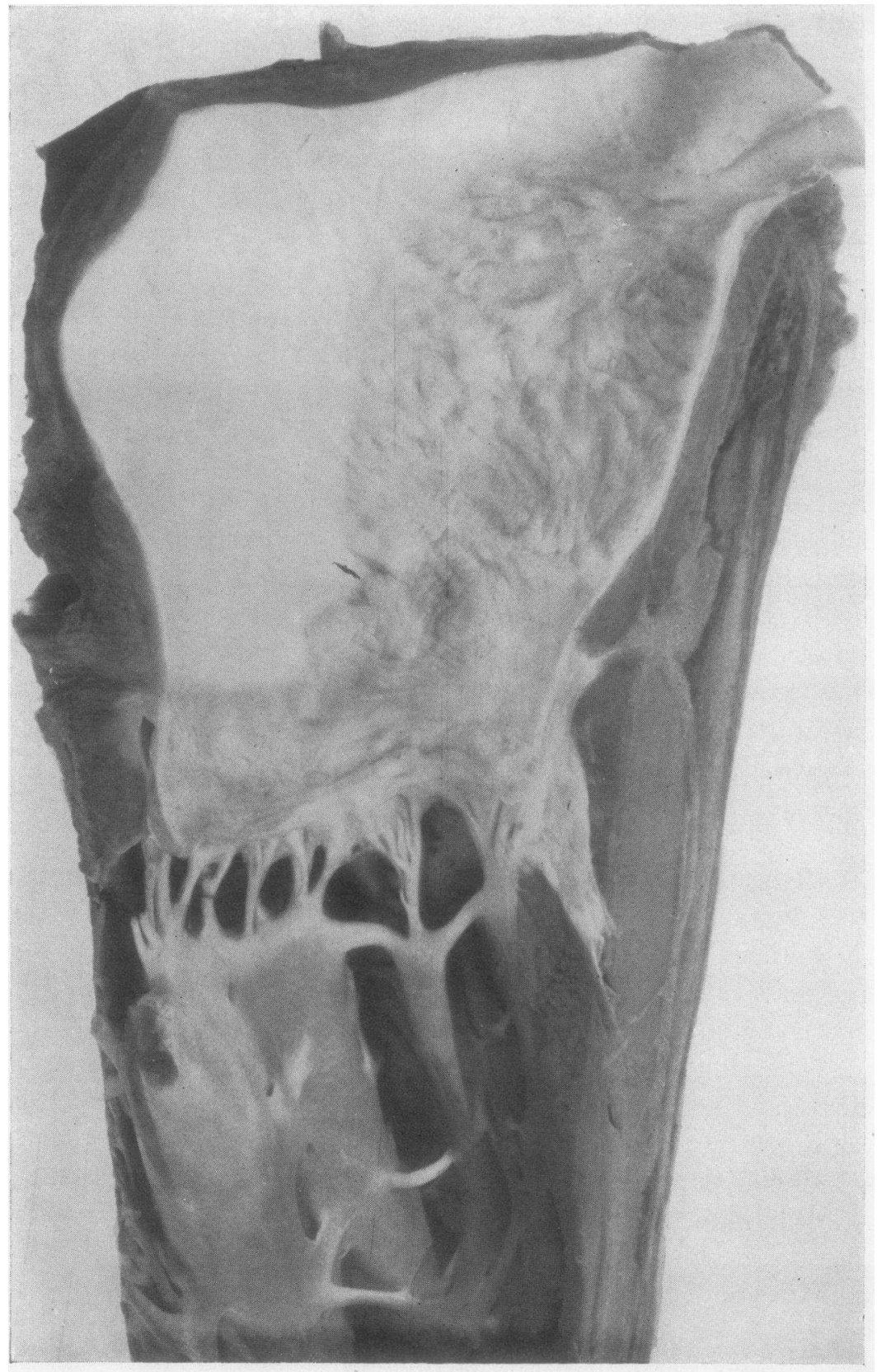

Fig. 1. Gross Appearance of the Mitral Leaflet and the Endocardium in CASE I

The endocardium is markedly thickened with shortening of the valve and the chordae tendineae. 
5. Certain aspects of the nature of circulatory failure in rheumatic heart disease are discussed. The evidence presented in this study and previous observations reported in the literature do not support the conception that the rate of blood flow is increased in circulatory failure due to rheumatic heart disease, nor that the beneficial effect of digitalis is manifested by its capacity to reduce the cardiac output.

We are indebted to Miss Rose Shore with whose aid this investigation was carried out, and to Dr. F. B. Mallory for the photographs of the gross pathologic specimens.

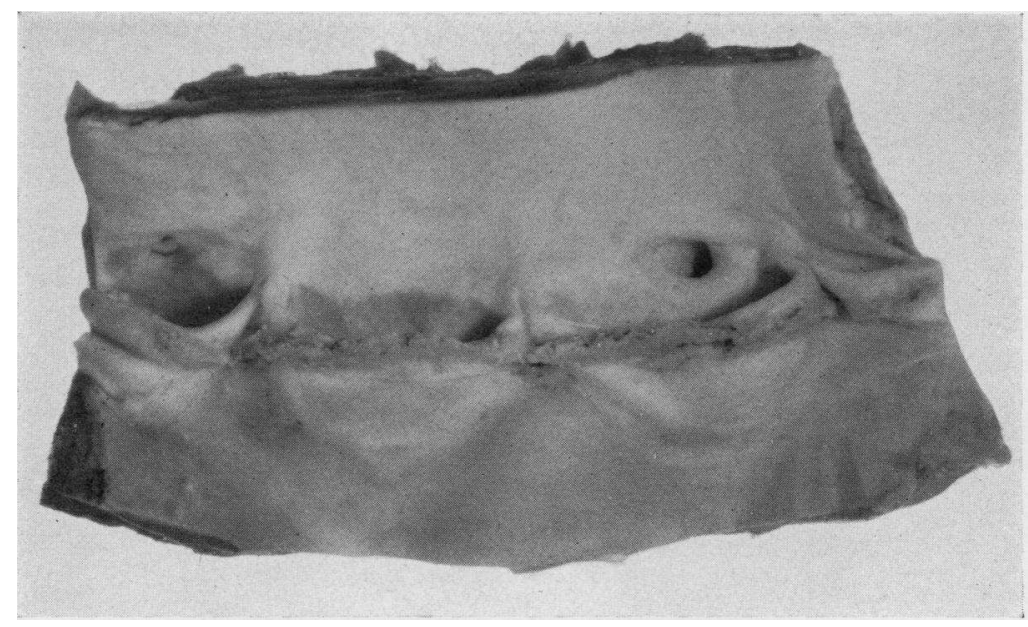

Fig. 2. Gross Appearance of the Aortic Valve in Case I

Thickening and retraction of the leaflets with superimposed fresh vegetations are present.

\section{PROTOCOLS}

Case I. The patient was a 14-year-old school girl who for 3 years had had dyspnea and was fatigued easily on exertion. Two months after the onset of these complaints she was told she had a "leaking" heart valve. Six months before she was studied dyspnea became worse, edema developed, and there were signs of cardiac decompensation, rheumatic heart disease, mitral stenosis and regurgitation, and aortic regurgitation. Under digitalization she improved greatly and developed a capacity to perform limited activity. Her condition remained unchanged for 6 months, when again she became dyspneic and fatigued on slight 
exertion. On her entry to the hospital (November 26,1928 ) the physical examination showed a well developed girl lying comfortably when flat in bed. The lips were of normal color. The tonsils were somewhat enlarged. Over the precordium

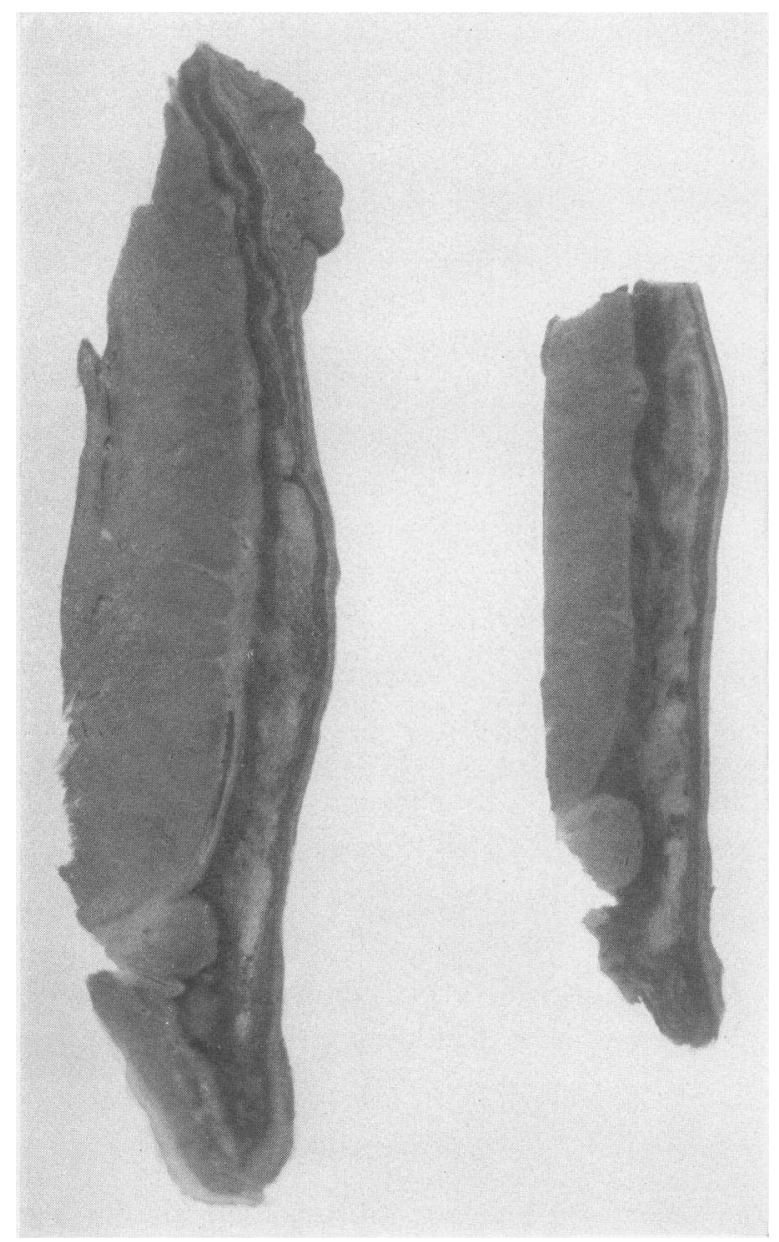

Fig. 3. Gross Appearance of Section of the Myocardium and the Thickened Pericardium in Case I

there was a diffuse heaving impulse. The apex impulse was in 5 th space $10 \mathrm{~cm}$. to left of the midsternal line. No thrills were felt. The cardiac sounds were loud, regular, with frequent extrasystolic beats. At the apex there was a blowing 


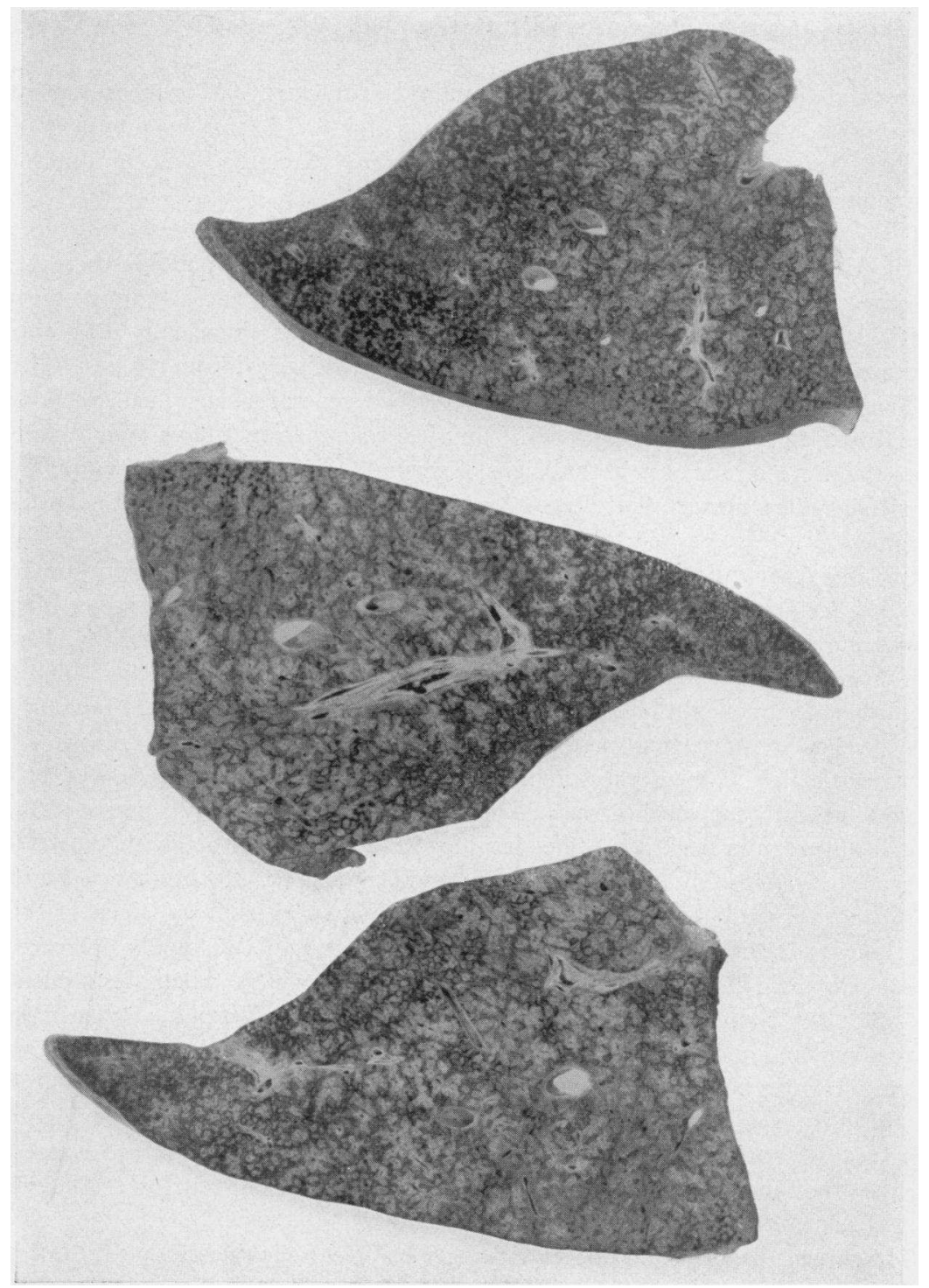

Fig. 4. Gross Appearance of Sections of the Liver from Case I Extensive central necrosis is present 
systolic and a rumbling diastolic murmur; at the base a rough systolic murmur. The lungs, abdomen, and extremities were normal.

The urine and blood were normal.

Roentgen-rays of the heart showed generalized enlargement. The measurements were: great blood vessels $-4.1 \mathrm{~cm}$.; maximum right $-5.2 \mathrm{~cm}$.; maximum left$10.5 \mathrm{~cm}$.; transverse diameter $-13.4 \mathrm{~cm}$.; longitudinal diameter $-27.2 \mathrm{~cm}$.; internal diameter chest $-24.2 \mathrm{~cm}$.

On November 29 and 30 , she received a total of 0.84 gram of digitalis in the form of the tincture which corresponded to 12 cat units. Following this there was observed definite although not marked subjective and objective improvement, particularly as regards dyspnea and weakness. She was given daily 0.14 gram digitalis, in powder form, for 3 weeks when she was discharged from the hospital.

The day following her discharge she developed general malaise, nausea, fever, sore throat and migratory joint pain. Physical examination 6 days later differed from the previous one only in that signs of general toxicity and an additional faint aortic diastolic murmur were noted. A white blood cell count was 13,100 per cubic millimeter.

She was given salicylates and improved somewhat for a few days. On January 3,1929 , her urine showed a few red blood cells and granular casts, but her blood pressure was normal. The nonprotein nitrogen was $36 \mathrm{mgm}$. per $100 \mathrm{cc}$. of blood. Her urine subsequently became normal except for a slight trace of albumin. The phenolsulphonephthalin excretion was 60 per cent in 2 hours. January 5 she developed substernal pain, a pericardial friction rub and dulness and râles at the left base of the lung. During the next 3 weeks there was little change, except that she became orthopneic. The pericardial rub persisted. A blood culture was negative. She developed secondary anemia with $2,610,000$ red cells per cubic millimeter and 65 per cent of hemoglobin. Roentgen-ray showed "probable pericardial effusion," but there were no definite clinical signs of this. On January 26 edema of the ankles was noticed and this gradually increased. There was little change in her condition until February 16, when she suddenly became very dyspneic and developed general anasarca. Morphine and caffeine were given, and on February 18 a venesection was done. The venous pressure was $14 \mathrm{~cm}$. of water before and $8.5 \mathrm{~cm}$. of water after the removal of $500 \mathrm{cc}$. of blood. At this time she showed signs of tricuspid insufficiency with pulsating jugular veins and a large liver. No response to histamine injection was obtained, suggesting that the tone of the peripheral vascular bed had been entirely lost. She died on February 19.

The clinical diagnosis was acute exacerbation of a chronic rheumatic pancarditis, chronic rheumatic endocarditis, mitral stenosis and regurgitation, aortic regurgitation, tricuspid regurgitation, adhesive pericarditis, congestive heart failure.

Electrocardiograms showed the following: November 12, 1928, S-A tachycardia, rate 110, P-R 0.18 second. November 28, 1928, S-A tachycardia, rate 110, P-R 0.14 second. Numerous premature ventricular beats. December 1, 1928, 
N.S.R., rate 70; P-R 0.16 second, $\mathrm{QRS} 0.06$ second, $\mathrm{P}_{1} \mathrm{P}_{3}$ notched, $\mathrm{P}_{3}$ diphasic, $\mathrm{T}_{3}$ inverted. December 3, 1928, slight sinus arrhythmia, rate 70, P-R 0.16 second, QRS 0.08 second, $L_{1}$ premature ventricular beats followed by increased P-R interval ( 0.36 second); $\mathrm{L}_{2} \mathrm{~L}_{3}$ premature ventricular beats followed by retrograde $P$ waves and ventricular escape. $P_{1} P_{2} P_{3}$ notched. $P_{2}$ diphasic. $T_{3}$ inverted. February 5, 1929, tachycardia, rate 110, P-R 0.18 second, QRS 0.06 second, T upright, all leads.

At autopsy there was about $300 \mathrm{cc}$. of bile-stained green fluid in the peritoneal cavity. Several petechial hemorrhages were seen in the transverse mesocolon. The liver was enlarged and weighed 1510 grams. The heart and the completely adherent pericardium were tremendously enlarged, and their transverse diameter was about three-quarters of the internal diameter of the chest. The lower part of the left lung was pushed up. The pericardial cavity was obliterated and the adhesions extended over the left dome of the diaphragm and the thoracic aorta. The heart and pericardium weighed 1080 grams (figs. 1, 2 and 3). Both auricles and ventricles were dilated; there was tremendous increase in the width of the heart wall. The muscle was moderately soft and gray to yellow in color. Outside of the muscle there was a gray granular area nearly $1 \mathrm{~cm}$. in thickness. The mural endocardium was roughened and thickened especially in the left atrial chamber. The mitral valve was much thickened and deformed, and the chordae tendinae were shortened. Along the edges of the aortic and tricuspid valves there were many recent vegetations; there were also thickening and retraction of the leaflets. Some of the minute granulations extended over the mural endocardium. The measurements of the circumference of the valves and heart walls were as follows: tricuspid valve $10.5 \mathrm{~cm}$., pulmonary valve $7.0 \mathrm{~cm}$., mitral valve $9.0 \mathrm{~cm}$., aortic valve $5.7 \mathrm{~cm}$.; the thickness of the left ventricle $2.5 \mathrm{~cm}$. and $0.8 \mathrm{~cm}$. pericardium, right ventricle $0.6 \mathrm{~cm}$. and $0.5 \mathrm{~cm}$. pericardium.

The lungs were essentially negative. The spleen was firm, purplish in color and weighed 195 grams. The surface of the cut sections of the liver showed many small dense yellow areas forming an interlacing network (fig. 4).

Anatomic diagnosis: Pancarditis; chronic passive congestion of liver.

Case II. A 25-year-old, colored girl was in the hospital from May 16 to August 1, 1928, suffering from acute rheumatic fever. During her stay she developed signs of aortic regurgitation. After discharge her chief symptom was "indigestion"-gastric distress and gas, accompanied by palpitation, which gradually became worse. She was dyspneic on slight exertion, but exhibited no other cardiac symptoms. Physical examination on entry, December 4, 1928, showed nothing remarkable except the condition of the heart. It was enlarged; the left border of dulness was $10 \mathrm{~cm}$. from the mid sternal line or $1.5 \mathrm{~cm}$. outside the point of maximum impulse. At the apex there was a pre-systolic murmur and a loud first sound. In the aortic area there was a short blowing systolic and a loud blowing diastolic murmur, which was also heard along the left sternal border. The lungs were clear. No edema was noted. 
The urine was repeatedly negative. Forty per cent of phenolsulphonephthalein was excreted in 2 hours. The blood was normal.

Roentgen-ray of the heart showed generalized enlargement with the following measurements; great blood vessels, $5.2 \mathrm{~cm}$.; maximum right, $6.8 \mathrm{~cm}$.; maximum left, $7.9 \mathrm{~cm}$.; transverse diameter, $12.6 \mathrm{~cm}$.; longitudinal diameter $15.5 \mathrm{~cm}$.; internal diameter chest, $23.7 \mathrm{~cm}$.

Electrocardiograms showed the following: December 5, 1928, N.S.R., rate 80; P-R 0.16 second, QRS 0.10 second, $\mathrm{T}_{2}$ and $\mathrm{T}_{3}$ inverted. January 3, 1929, N.S.R., rate 70, P-R 0.14 second, QRS 0.06 second, T inverted in all leads.

The record of digitalis which she received and the results of the tests are as follows:

December 24, when the patient bent from a reclining to a sitting position 15 times in succession her pulse rate rose from 75 to 100 where it remained for 4 minutes. She was somewhat tired but had no true dyspnea.

On December 28, she received a total of 1.0 gram of digitalis leaf (14 cat units), following which she was nauseated and vomited for 6 hours. On December 31, she was given daily 0.14 gram of digitalis leaf until February 8.

On December 31 after the exercise test the pulse rate increased to 86 from 68 , but fell to 70 within a minute. There was no fatigue. A repetition of the test on February 8 was essentially the same.

The patient took no digitalis from February 8 to March 2. On February 18th after the exercise test the pulse rate rose from 82 to 100 but returned to normal in one minute. There was slight dyspnea and palpitation. Another test on March 1 was performed without producing definite symptoms and with a similar rise in pulse rate.

On March 2 and 3 she again received 1.0 gram of digitalis and this was followed by a daily dose of 0.14 gram. A functional test on March 12 was similar to that of December 31.

Diagnosis: Rheumatic heart disease; mitral stenosis and regurgitation; aortic regurgitation; marked cardiac hypertrophy.

Cuse III. This patient was a 28-year-old, single, unoccupied man, who had had three attacks of rheumatic fever at 7, 13, and 17 years of age. After the first attack his heart was damaged but he experienced no symptoms as a result of this until after his last attack, since when he has been dyspneic, but was able to work until about a year ago. For one year he had been troubled by some orthopnea and cough, but no edema. Six weeks before entry he suffered from an attack of hemoptysis. He entered the hospital on November 13, 1928 on account of an acute attack of dyspnea with cough of 12 hours duration.

Physical examination was negative except for his heart which showed marked general enlargement. The sounds were of good quality. At the apex there were loud systolic and diastolic murmurs. A blowing diastolic murmur was heard in the aortic area and along the left sternal border. There was a systolic thrill and a 
rough systolic murmur in the right second interspace. The fingers were slightly clubbed.

Laboratory studies showed the urine and blood to be normal. Roentgen ray photograph of the heart showed uniform enlargement; great blood vessels measured $6.0 \mathrm{~cm}$.; the diameters were: maximum right, $5.7 \mathrm{~cm}$.; maximum left, $10.9 \mathrm{~cm}$.; transverse, $16.2 \mathrm{~cm}$.; longitudinal, $18.7 \mathrm{~cm}$.; internal diameter of chest, $29.4 \mathrm{~cm}$.

Electrocardiograms showed the following: November 19, 1928, N.S.R., rate 90, P-R 0.20 second. Question of partial heart block, QRS 0.06 second, $R_{1}$ slurred. December 6, 1928, N.S.R., rate 80, P-R 0.16 second, QRS 0.08. December 14, 1928 , N.S.R., rate 100, P-R 0.18 second, $Q R S 0.07$ second, $T_{2}$ and $T_{3}$ diaphasic.

The amounts of digitalis received by the patient and the results of the exercise tests are given below:

December 4. On walking slowly on a level, his pulse rose from 105 to 145 and in 2 minutes returned to 120 . Upon climbing one flight of stairs slowly he became definitely dyspneic and his pulse rose to 155 , and over a period of 10 minutes gradually subsided to 130 .

On December 10 and 11 he received a total of 1.4 gram of digitalis leaf (20 cat units). He received then daily 0.21 gram of the leaf.

On December 12 the exercise test of December 4 was repeated. On walking on a level his pulse rose from 75 to 120 , and remained at 115 on standing. On climbing 1 flight, his pulse rose to 145 but returned to 110 in 3 minutes. There was no dyspnea.

On December 26 the test was repeated. On walking, his pulse rose from 70 to -85 where it remained. On climbing 1 flight of stairs, it rose to 115 but returned to 85 within 2 minutes. There was no dyspnea.

On January 11 and 12 digitalis was omitted because of anorexia. From January 13 to 22 he received 0.14 gram daily. The results of a functional test on January 22 were similar to those of December 26.

From January 23 to February 13 he received no digitalis. On January 31, a functional test gave results similar to those of the two preceding ones except that he developed slight dyspnea and palpitation on exertion. On February 13 another test was performed with results resembling the initial test of December 4 , that is to say, a marked and prolonged rise in pulse rate with dyspnea and palpitation. On February 14 and 15 he received a total dose of 1.4 gram of digitalis leaf and following this received 0.14 gram daily. Functional tests on February 15 and March 9 were performed in similar fashion to those made during his initial period of digitalization.

He showed little change during the first part of his stay in the hospital. On January 6 he developed mild tonsillitis, and subsequently at intervals, slight pains and stiffness in some of his joints but no objective manifestations. On March 30th a fever began, he complained of pain in his right chest which showed signs of early pneumonia. The white blood cells numbered 20,000 per cubic millimeter. 
A blood culture was negative. His general condition rapidly became worse, his pulse and respiration rose markedly, and he died on April 3,1929. No autopsy was performed.

Diagnosis: Rheumatic heart disease; mitral stenosis and regurgitation; aortic stenosis and regurgitation; terminal pneumonia.

Case IV. The patient, a 22-year-old, female clerk, suffered a severe attack of rheumatic fever at 10 years of age, since when she had been dyspneic on exertion. She had experienced several mild attacks of joint pain, the last one about 3 years ago. One month before entry she had an attack of hemoptysis of about 2 cupfuls of frothy red blood. She entered the hospital on January 14, 1929.

Physical examination showed an orthopneic, pale girl, Her throat was congested. The heart was somewhat enlarged. A systolic thrill was noted to the left of the sternum in the third interspace. The sounds were loud and regular; there were pre-systolic and systolic murmurs at the apex, a blowing diastolic murmur in the aortic area and along the left border of the sternum, and a rough systolic murmur at the base, loudest in the pulmonic area. The lungs were clear. No edema was observed.

The urine was repeatedly negative.

White blood cells on entry numbered 25,500 per $\mathrm{cm}$. Blood culture and Kahn tests were negative.

Roentgen-ray photograph of the heart showed general enlargement and a mitral shape. The great blood vessels measured $4.2 \mathrm{~cm}$. The diameters were: maximum right, $4.5 \mathrm{~cm}$.; maximum left, $9.1 \mathrm{~cm}$.; transverse, $12.2 \mathrm{~cm}$.; longitudinal, $14.6 \mathrm{~cm}$.; internal diameter of the chest, $23.5 \mathrm{~cm}$.

Electrocardiogram taken on January 29 showed normal sinus rhythm, rate 60 , P-R 0.16 second, QRS 0.06 second, $\mathrm{P}_{1}$ and $\mathrm{P}_{2}$ notched, $\mathrm{P}_{3}$ diphasic.

Slight fever present on entry, promptly vanished. The elevated white blood cell count rapidly fell to normal. She was perfectly comfortable in bed after the first day and exhibited no dyspnea or orthopnea at rest. The thrill over the pulmonic area disappeared and the rough systolic murmur in this region became less marked.

The amounts of digitalis that she received and the results of the exercise tests are recorded below.

On January 29 and February 13 tests were performed by having her bend rapidly from a reclining to a sitting position 12 times. During these tests her pulse rate rose from an initial level of 80 to 100 and 135 respectively, but returned to 80 within one minute. She complained of slight dyspnea and palpitation. On February 15 she received 1.0 gram of digitalis leaf (14 cat units). On February 15 a test was again performed without the development of dyspnea or palpitation and with an increase of pulse rate of only 10 points, from 58 to 68 .

From February 16 to 21 she received 0.14 gram, and from February 22 to March 2, 0.07 gram daily of digitalis. On March 2 she showed a bigeminal pulse. Digi- 
talis was omitted for 4 days, and resumed on March 6, when she received 0.14 gram for 2 days 0.07 gram for 3 days and then 0.14 gram daily until March 29th. A functional test on this date yielded results similar to those obtained on February 15.

From March 30 to April 20 she received no digitalis. On April 20 a test showed a rise in pulse rate from 80 to 84 and there was perhaps trivial dyspnea.

On April 21 to 22 she received a total of 1.0 gram of digitalis and 0.14 gram daily until April 29 and 0.07 gram on April 30. On April 30 she showed anorexia and cardiac irregularity; digitalis was omitted until May 9. On May 9 and 10 she received 0.21 gram and 0.07 gram daily thereafter.

Functional tests on April 23 and 25 showed practically no pulse rise after exercise and no subjective symptoms whatsoever.

The patient showed little clinical change throughout the remainder of her stay in the hospital. She was discharged on May 15, 1929.

Diagnosis: Rheumatic heart disease; mitral stenosis and regurgitation; aortic regurgitation; question of pulmonic stenosis.

\section{BIBLIOGRAPHY}

1. Cohn, A. E., J. Am. Med. Assoc., 1915, lxv, 1527. Clinical and Electrocardiographic Studies on the Action of Digitalis.

2. Hoffmann, A. Funktionelle Diagnostik und Therapie der Erkrankungen des Herzens und der Gefässe. Julius Springer, Berlin, 1911, p. 263.

3. Mobitz, W., Deutsch. Arch. f. klin. Med., 1927, clvii, 359. Die Ermittlung des Herzschlagvolumens des Menschen durch Einatmung von Äthyljodidampf IV. Klinisch kompensierte Veränderungen des Herzens und der Gefässe und beginnende Kreislaufdekompensation ohne Lungenveränderungen.

4. Am. Heart J., 1927, ii, 202. A Nomenclature for Cardiac Diagnosis, Approved by the American Heart Association.

5. Field H., Jr., Bock, A. V., Gildea E. F., and Lathrop, F. L., J. Clin. Invest., 1924, i, 65. The Rate of the Circulation of the Blood in Normal Resting Individuals.

6. Keith, N. M., Rowntree, L. G., and Geraghty, J. T., Arch. Int. Med., 1915, xvi, 547. A Method for the Determination of Plasma and Blood Volume.

7. Weiss, Soma, Robb, G. P., and Blumgart, H. L., Am. Heart J., 1929, iv, 664. The Velocity of Bood Flow in Health and Disease, as Measured by the Effect of Histamine on the Minute Vessels.

8. Hatcher, R. A., and Brody, J. G., Am. J. Pharmacy, 1910, 1xxxii, 360. The Biological Standardization of Drugs.

9. Weiss, Soma, and Hatcher, R. A., J. Am. Pharm. Assoc, 1923, xii, 26. Study of a Digitalis Body Which is Eliminated Rapidly after its Intravenous Injection in the Cat. 
10. Bohnenkamp, H., Eismayer, G., and Ernst, W., Ztschr, f. Biol., 1928, lxxxvii, 489. Die Energieumwandlungen im Herzmuskel. IV. Mitteilung. Arbeit und Sauerstoffverbrauch des Froschherzens.

11. Plesch, J., Ztschr. f. exp. Path. u. Therap., 1909, vi, 380. Haemodynamische Studien.

12. Lundsgaard, C., Deutsch. Arch. f. klin. Med., 1916, cxviii, 513. Untersuchungen ueber das Minutenvolumen des Herzens bei Menschen. II. Patienten mit Herzklappenfehlern.

13. Meakins, J., Dautrebande, L., and Fetter, W. J., Heart, 1923, x, 153. The Influence of Circulatory Disturbances on the Gaseous Exchange of the Blood. IV. The Blood Gases and Circulation Rate in Cases of Mitral Stenosis.

14. Rabinowitch, I. M., Arch. Int. Med., 1925, xxxvi, 239. The Output of the Heart per Beat in Heart Disease.

15. Lauter, S., and Baumann, H., Klin. Wchnschr., 1929, viii, 263. Zur Theorie der Herzinsuffizienz und der Digitaliswirkung.

16. Schwarz, H., Klin. Wchnschr., 1929, viii, 599. Zur Theorie der Herzinsuffzienz und der Digitaliswirkung.

17. Eppinger, H., Kisch, F., and Schwarz, H., Das Versagen des Kreislaufes. Berlin. Julius Springer, 1927.

18. Blumgart, H. L., and Weiss, Soma, J. Clin. Invest., 1927, iv, 149. Studies on the Velocity of Blood Flow. II. The Velocity of Blood Flow and its Relation to Other Aspects of the Circulation in Patients with Rheumatic and Syphilitic Heart Disease.

19. Blumgart, H. L., and Weiss, Soma, J. Clin. Invest., 1927, iv, 173. Studies on the Velocity of Blood Flow. IV. The Velocity of Blood Flow and its Relation to Other Aspects of the Circulation in Patients with Arteriosclerosis and in Patients with Arterial Hypertension.

20. Blumgart, H,L., and Weiss, Soma, J. Clin. Invest., 1927, iv, 199. Studies on the Velocity of Blood Flow. V. The Physiological and Pathological Significance of the Velocity of Blood Flow.

21. Blumgart, H. L., and Weiss, Soma, J. Clin. Invest., 1928, v, 343. Clinical Studies on the Velocity of Blood Flow. IX. The Pulmonary Circulation Time, the Velocity of Venous Blood Flow to the Heart, and Related Aspects of the Circulation in Patients with Cardiovascular Disease.

22. Blumgart, H. L., and Weiss, Soma,. J. Clin. Invest., 1928, v, 379. Clinical Studies on the Velocity of Blood Flow. X. The Relation Between the Velocity of Blood Flow, the Venous Pressure and the Vital Capacity of the Lungs in Fifty Patients with Cardiovascular Disease Compared with Similar Measurements in Fifty Normal Persons.

23. Wollheim, E., Klin. Wchnschr., 1928, vii, 1261. Kompensation und Dekompensation des Kreislaufs. 
24. Cushny, A. R., The Action and Uses in Medicine of Digitalis and its Allies. London, 1925.

25. Eppinger, H., von Papp, L., and Schwarz, H., Uber das Asthma Cardiale; Versuch zu einer peripheren Kreislaufpathologie. Julius Springer, Berlin, 1924, p. 191 .

26. Harrison, T. R., and Leonard, B. W., J. Clin. Invest., 1926, iii, 1. The Effect of Digitalis on the Cardiac Output of Dogs and its Bearing on the Action of the Drug in Heart Disease.

27. Cohn, A. E., and Stewart, H. S., J. Clin. Invest., 1928, vi, 53. The Relation Between Cardiac Size and Cardiac Output per Minute Following the Administration of Digitalis in Normal Dogs.

28. Burwell, C. S., Neighbors, DeW., and Regen, E. M., J. Clin. Invest., 1927, v, 125. The Effect of Digitalis upon the Output of the Heart in Normal Man.

29. Cohn, A. E., and Stewart, H. S., J. Clin. Invest., 1924, i, 97. Evidence that Digitalis Influences Contraction of the Heart in Man.

30. Hochrein, M., and Meier, R., Munch. Med. Wchnschr., 1927, lxxiv, 1925. Ueber neuere Methoden zur Bestimmung der arteriellen Blutgeschwindigkeit.

31. Kininmonth, J. G., Quart. J. Med., 1928, xxi, 277. The Circulation Rate in Some Pathological States, with Observations on the Effect of Digitalis.

32. Weiss, Soma and Blumgart, H. L., J. Clin. Invest., 1929, vii, 11. The Effect of the Digitalis Bodies on the Velocity of the Blood Flow through the Lungs and on Other Aspects of the Circulation. A Study of Normal Subjects and Patients with Cardiovascular Disease. 